\title{
Thinking about National Standards in Science Education
}

\section{Catherine Milne ${ }^{\circledR}$ United States}

In this paper I present a critical reflection on the rationale and history of the Next Generation Science Standards (NGSS), which has sometimes been presented as the US version of a vision for a standardized science curriculum. I explore how the monograph, The Framework for K-12 Science Education, established the groundwork for the Next Generation Science Standards. I argue that crisis narratives often drive the arguments for standardization but in the US there was also an argument of the need to build a level of national uniformity in the content and practices that are presented to students as a tool for ensuring that children and youth have equitable access to important knowledge. However, at the same time educators have a responsibility for ensuring that homogenization achieved through standards does not enshrine the very inequities and ideologies public education seeks to change.

Keywords: standards; NGSS; national curriculum; practices; crisis narratives.

As an educator, I understand that many countries, including Brazil, have some form of national education guidelines that function as a form of national curriculum. The reasons countries decide to enact such guidelines can be varied. They may include a desire to build a level of national uniformity in the content and practices that are presented to students. Another reason for national guidelines might be the desire to improve student performance on international competitions, such as the Programme for International Student Assessment (PISA), and/or in response to "crisis narratives", stories of how children and youth today are no longer as able as previous generations and there is an immediate need to address such poor performances (Edwards, 2008). But as Edwards notes, crisis narratives are not new. They have been part of the discourse of education since education became a publically funded enterprise.

Crisis narratives justify the establishment of different models of schooling such as the charter school movement in the US and the commercialization of standardized assessments. Indeed, standardized forms of education are designed to reproduce specific cultural norms and social order. And disciplinary technologies of standardized curricula and associated high stakes testing can also have the effect of leading teachers to feel that they need to adopt pedagogies that achieve the performance expectations of state and national systems of education in the process subjecting students to a process of sorting 
that labels them as successes or failures, labels which have implications for their capacity to achieve specific goals inside school and beyond. So there often exists a tension for educators between seeing standards as a tool for ensuring that children and youth within a national system have equitable access to important knowledge while also ensuring that homogenization does not enshrine the very inequities and ideologies they are seeking to change.

In this paper, I seek to use the development of the current version of what could be thought of as the US version of national science education standards, the Next Generation Science Standards, with the goal that the reader will make connections with, and ask questions of, moves in Brazil for a new national science curriculum. In the US, State rights preclude the imposition of a national curriculum but federal funding can be leveraged, as was the case with the Race to The Top legislation, to make it very attractive for States to engage with a process of standardization.

\section{Standards, benchmarks and science education in the US}

Developing a set of standards is the first step towards a potential national curriculum. Standards can be thought of as statements of a vision for implementing practices, cross-cutting concepts and core ideas that, according to the authors of the Next Generation Science Standards (NGSS), constitute a high quality science education for students (Achieve, 2013). The NGSS represent an updating of the 1996 National Science Education Standards (NSES) (NRC, 1996).

In the 1990s two important documents, which explored the role of standards and benchmarking in science education, the NSES and the Benchmarks for Science Literacy, were released in the United States (AAAS, 1996). Even though there is a history in the US of science education standards and benchmarks, not everyone is enamored with standards or benchmarks. Some argue that standards seek to make knowledge a commodity and, in the process, learners become less differentiated as a singular cultural perspective tends to be emplaced (Slater \& Griggs, 2015). Angela Calabrese Barton (1998) reflected on this very issue when she noted that standards and benchmarks communicate an expectation that even if students are provided some leeway to explore ideas and construct some personal meanings within science, there remains "something to be known in a particular way" because there exists a particular reality of science that is "abstracted from any local context" in standards and benchmarks (p. 529). In exploring the historical development of the NGSS, I want to revisit this claim almost twenty years later. While the publication of the NSES and the Benchmarks in the 1990s provided educators with a context for discussions and actions around science education and standards, in the 2000s the National Research Council (NRC) sought to explore further some of the areas that intersected science and science education and initiated a number of studies/publications:

Taking Science to School: Learning and Teaching Science in Grades K-8 (2007)

This monograph has the goal of reviewing the current state of understanding 
about how children learn science, which helps to explain its focus on Kindergarten (5-6 years old) to Grade 8 (13-14) years) of schooling. It focused on questions such as the role that specific resources play in learning science and whether children learn about science outside of formal education contexts.

Learning Science in Informal Environments: People, Places and Pursuits (2009)

This monograph explored the nature of informal learning across the age spectrum and sought to develop an evidence base for developing a framework for further exploring informal learning in a more systemic way.

American's Lab Report: Investigations in High School Science (2005)

This monograph focused on laboratory investigations asking what they contributed and how they contributed to science learning. The monograph also explored the current state of laboratory spaces as contexts for Science learning.

Many of the studies reported in these monographs were commissioned because of a perception that, since public understanding of science was low, there was a need in order to have a sense of the field to find out what was known about learning in science in various contexts. With respect to laboratory experiences (NRC, 2005) for example, the authors acknowledged the challenge of recognizing the potential contribution laboratory experience could make to science understanding and achievement of students when high stakes tests, such as PISA and TIMSS (Trends in Mathematics and Science Study), were not designed to measure "progress to all the goals of laboratory experiences" ( $p$. 44). Beyond mastery of science content and developing scientific reasoning skills, which potentially could be assessed with a test, the committee identified other areas of learning that laboratory work could support, which are more difficult to assess with traditional text-based tests, including supporting students to understand the "complexity and ambiguity of empirical work", developing practical skills, understanding the nature of science, cultivating an interest in science and learning science and developing teamwork abilities (p. 44). Because of the challenges, such as supplying uniform kits of science material to students and training experts to score the task associated with including performance tasks (hands-on tasks), performance tasks were considered too difficult for general implementation.

These monographs also suggested that there might be a need for the NSES to be revised. Interestingly, perhaps illustrative of the commodification of science education, the Carnegie Corporation of New York and the Institute for Advanced Study (both private foundations) called for the development of a common set of standards in science (NRC, 2012). The Carnegie Corporation took a lead role in ensuring a two-step process in developing these common science standards. Step one was the development of a framework which provided the rationale for a specific standards structure and step two was the development of those standards. Further evidence for the commodification of science education came from educational leaders in the US government arguing to educational entrepreneurs the benefits of a national adoption of common standards that could accrue to them (Ravitch, 2013). 
The monograph, A Framework for K-12 Science Education (NRC, 2012), was the result of Step one, the framework from which the science standards could be developed. The framework identified three dimensions: practices, cross cutting concepts and disciplinary core ideas that, according to the committee that negotiated the framework, helped to frame the science knowledge that was of most worth. The committee also argued the framework took into account two major goals of K-12 science education: educating all students in science and engineering and providing the foundational knowledge for those who will become scientists, engineers, technologists and technicians of the future. The authors described the Framework as providing, "a broad description of the content and sequence of learning expected of all students by the completion of high school" (p. 8).

The fact that one of the dimensions of the Framework was based on practice in this new argument for a specific structure for science education in the US was very attractive to me, and I think to other educators, because it raised the possibility of moving pedagogy and assessment in science education away from a focus that valued only conceptual understandings to a focus that allowed space for students to engage in specific practices that are valued in science. As I have noted elsewhere (see Milne 2016), a focus on practice offers the possibility of learners being presented with the opportunity of experiencing science as something they can do in contrast to their typical experience of reproducing finished science which is usually the case with a focus on conceptual understandings. I also hoped that a focus on practice might present students with space and time in their science classes to identify with science as a set of practices that they could value.

My experience also had me agreeing with Jonathan Osborne (2014) that a practicebased approach, exclusive of specific details about specific practices, has the potential to provide a context for learners to begin to understand the relationship between claims and evidence, what constitutes compelling evidence that can be used to judge a claim and how claims provide the context for experimentation, in other words supporting students to develop an understanding of the epistemic basis of the culture and discipline of science. Also, a focus on practice would create a space for the development of the language function of procedure, which allows science and any set of instructions for that matter, to turn actions into text and, in another context, that text into action (see also Milne, 2011 for an exploration of the history of procedural language in science). Similar to Kathleen Stoehr's (2017) research on mathematics anxiety, a focus on practice would offer the possibility of students developing practical competency which could support them to see science as part of their identity. Of the other dimensions, cross cutting concepts represented "big ideas" such as energy and matter, stability and change, and structure and function, that allow teachers and students to move between disciplinary areas and disciplinary core ideas represented the important ideas in science, such as the idea that waves transfer energy without displacing matter in physical science, or from earth systems the idea that the Earth is constantly changing as its systems interact. 


\section{Interpreting the Framework for K-12 Science Education}

However, as I read through the Framework I was left with the question of who was the audience for this monograph? I found it to be so dense that I wondered how it could be considered user friendly for science teachers who I assumed constituted one of the main audiences for this monograph. At the time, I was teaching a course in curriculum and science teaching methods to graduate students studying to become secondary science teachers and I realized the importance to them as prospective science teachers of reading the Framework. However, I understood also that just reading the document would not mean that these pre-service teachers would develop a deep familiarity with its arguments. The National Science Teachers' Association (NSTA) in the US published an NSTA Reader's Guide (Pratt, 2012), to help teachers and others unpack this document but that was such a dry document that I thought the students in the course could do better and produce a more engaging narrative. I wanted them to use both text and visual imagery in a graphic narrative style to communicate to each other and to other teachers the main arguments and position statements of the Framework (see Figure 1 for a breakdown of the focus taken from the Framework document).

\begin{tabular}{|l|}
\hline Contents of the Framework \\
\hline Part 1- A Vision for K-12 Science Education \\
\hline A New Conceptual Framework \\
\hline Guiding Assumptions and Organization of the Framework \\
\hline Dimensions of the Framework \\
\hline Dimension 1 - Scientific and Engineering Practices \\
\hline Dimension 2 - Cross Cutting Concepts \\
\hline Dimension 3 - Disciplinary Core Ideas (Physical Science) \\
\hline Dimension 3 - Disciplinary Core Ideas (Life Sciences) \\
\hline Dimension 3 - Disciplinary Core Ideas (Earth and Space Science) \\
\hline Dimension 3 - Disciplinary Core Ideas (Engineering, Technology and Applications of Science) \\
\hline Integrating the Three Dimensions \\
\hline Implementation: Curriculum, Instruction, Teacher Development, and Assessment \\
\hline Equity and Diversity in Science and Engineering Education \\
\hline
\end{tabular}

Figure 1. Content for the book, Framework for K-12 Science Education (NRC, 2013)

I was also attracted to graphic narratives because many of the students I taught were very comfortable in a text-based environment and I wanted them to use a different media which also challenged them to communicate to others the ideas embedded in each of the first eleven chapters of the Framework. Consequently, I assigned students working collaboratively in pairs to a specific chapter (see Figure 1). In the following sections, as I address the main points of the Framework (NRC, 2012) which informed the development of the Next Generation Science Standards (NGSS) (Achieve Inc., 2013), I show how the students interpreted these sections of the Framework. 


\section{A Vision for K-12 Science Education}
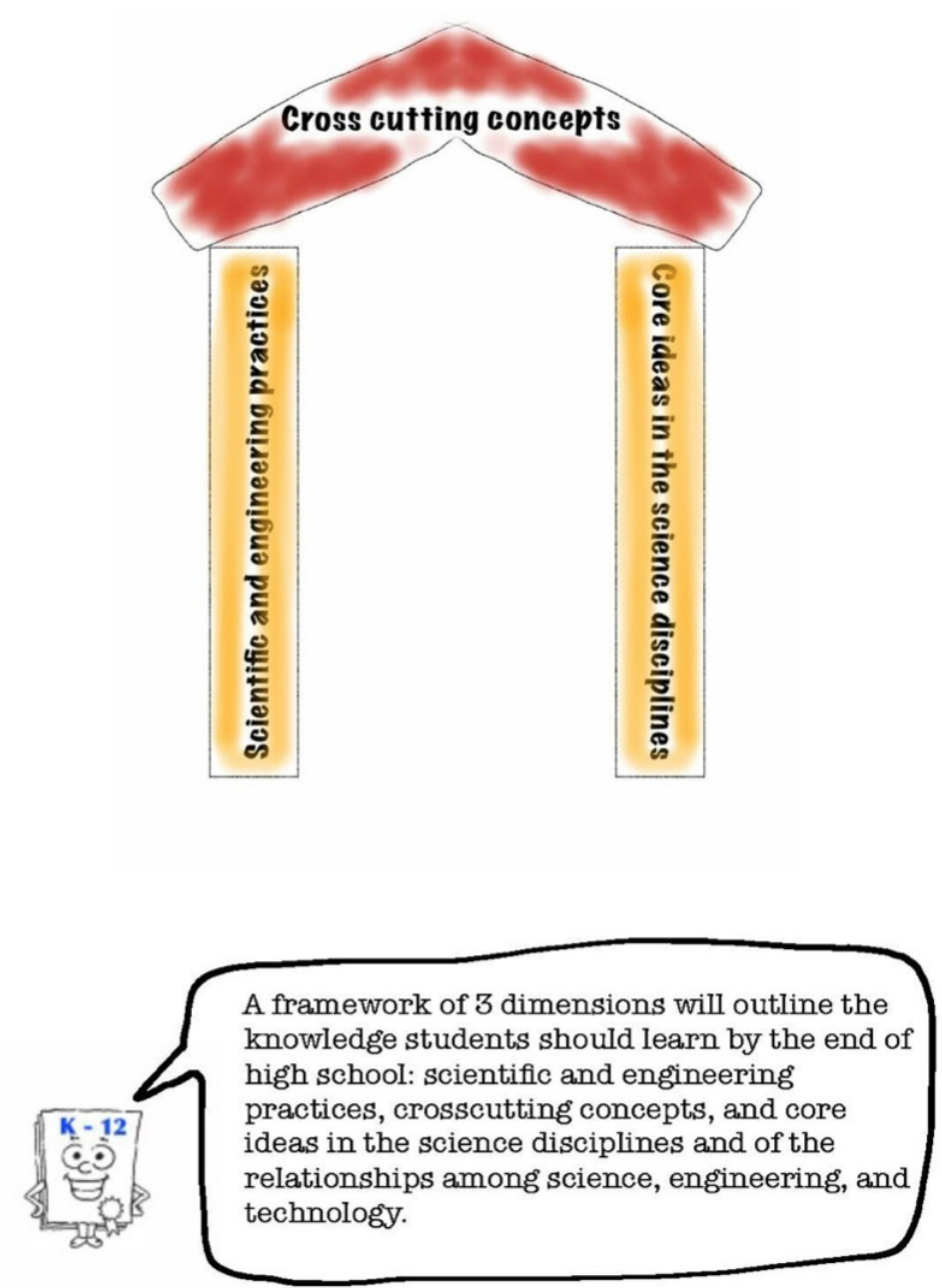

Figure 2. A focus on a limited number of core ideas (NRC, 2012)

Section One of the Framework outlined a vision for K-12 Science Education that was structurally different from previous national standards. This vision was designed to achieve two goals: to educate all students in science and engineering and to provide the foundational knowledge for those who will become scientists, engineers, technologists and technicians of the future. It was based on three dimensions, scientific and engineering practices, cross cutting concepts and core ideas in the disciplines (see Figure 2).

\section{Essential practices in Science and Engineering}

Dimension 1 in the Framework identified eight essential practices of scientists and engineers which included defining problems, developing models, planning and carrying out an investigation, analyzing and interpreting data, using mathematical and computational thinking, explaining and designing solutions, engaging in argument from evidence, and communicating information. A screen shot of one of the panels shows how the students assigned this section of the Framework turned it into a panel in 
a comic (see Figure 3).

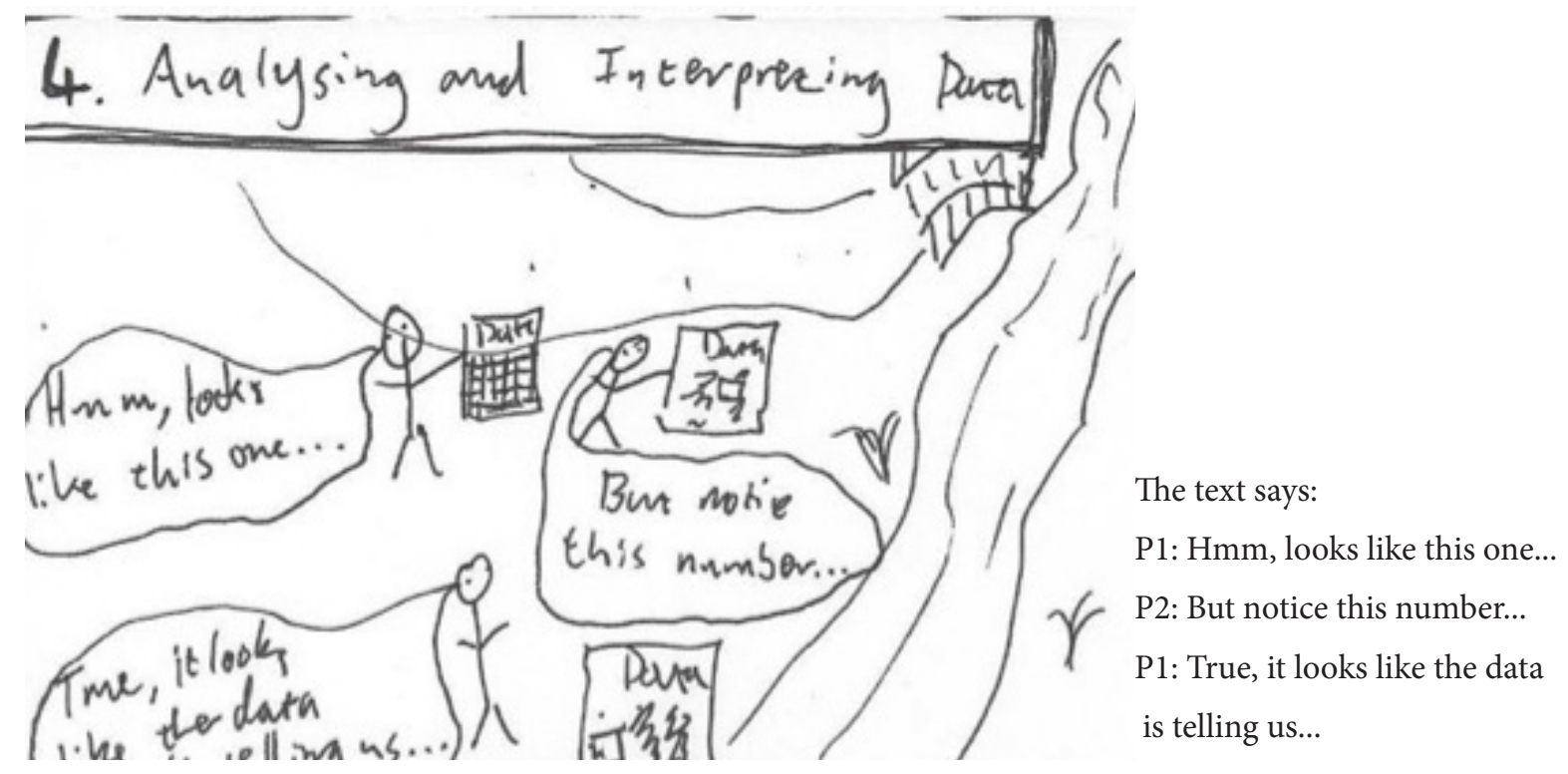

Figure 3. What it might look like to analyze and interpret data (NRC, 2012)

\section{Cross cutting concepts}

The panel (see Figure 3) communicates both the practice, analyzing and interpreting data, and how the assigned students interpreted that practice graphically. Note their dialogic representation of how data can be analyzed, an approach not captured in the formal Framework monograph. Their interpretation also communicates how practices and cross cutting concepts are interrelated because their graphic narrative of the chapter uses dialogue to link the cross cutting concept of analyzing and interpreting data with the practice of finding patterns. Such linkages highlight the challenge for the Framework of presenting practices and concepts as discrete constructs when, within the discipline of Science, there is a lot of overlap between such constructs. A possible limitation of the Framework is that the porous boundaries between these separate elements is not addressed by the Framework in its vision statement.

For Dimension 2, the Framework describes concepts that bridge disciplinary boundaries as cross-cutting concepts (see Figure 4). According to the authors of the Framework, these concepts were selected for their value across science and engineering. However, in school science, students are often expected to learn such concepts without explicit instruction. The lack of such instruction was one reason for the attention given to them as a separate dimension within the Framework. These cross-cutting concepts include patterns; cause and effect, mechanism and prediction; scale, proportion, and quantity; systems and system models; energy and matter, flows, cycles, and conservation; structure and function; stability and change. 


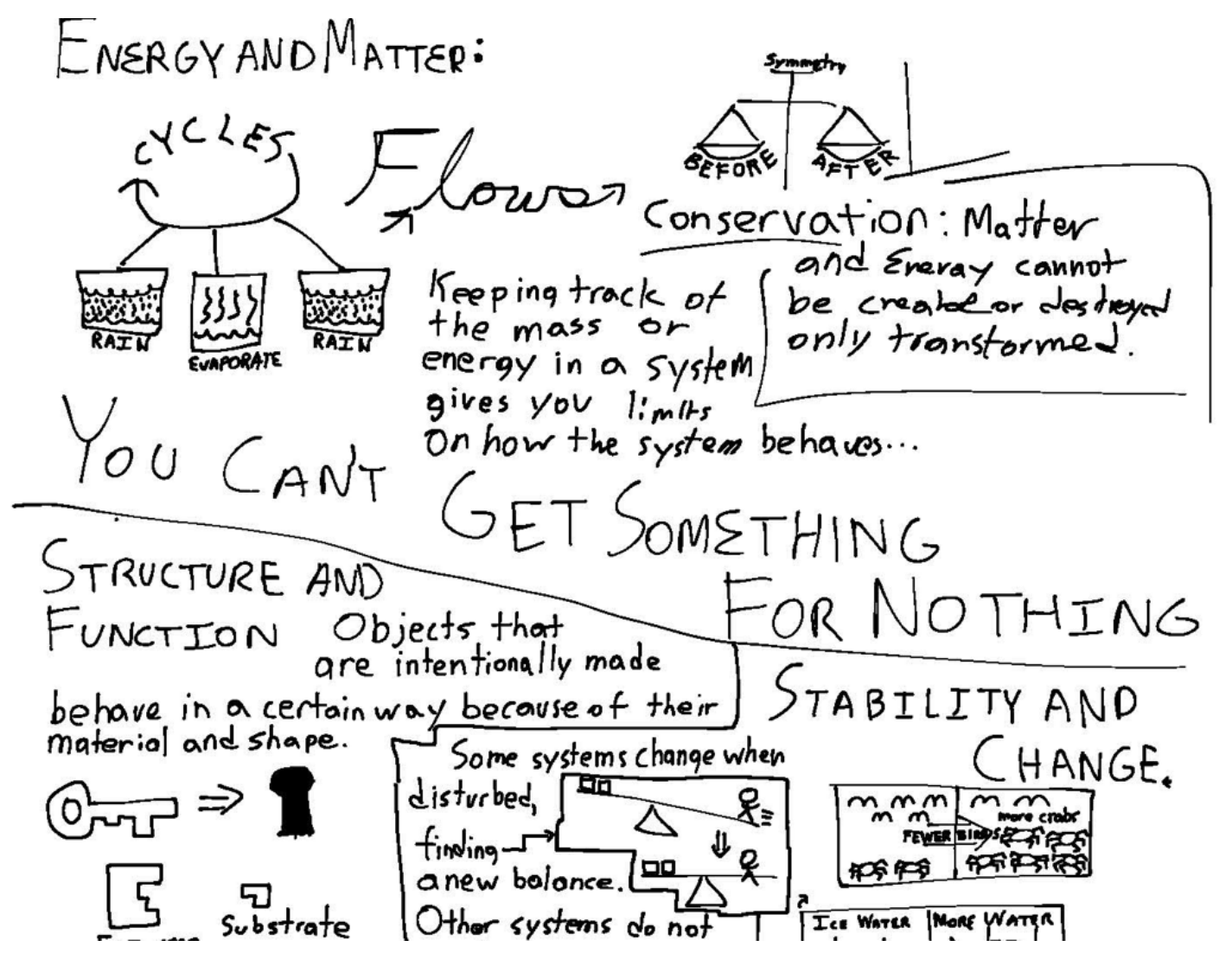

Figure 4. A sample of the cross cutting concepts (Dimension 2) in everyday language (NRC, 2012)

I had some reservations about claims made in this section of the Framework including, "In engineering, the goal is to design a system to cause a desired effect, so cause-and-effect relationships are as much a part of engineering as of science" (NRC, 2012, p. 88). Although I do not quibble with the notion that the concept of cause and effect is important in both engineering and science, my concern was with the assumption that the idea and application of cause and effect is the same for both disciplines. Since the nature of cause and effect in the disciplines is never problematized in the Framework, it is hard to know what the authors were thinking when they wrote about cause and effect when they did not explore whether the disciplines of engineering and science see cause and effect similarly or not. Eyetracking studies of babies show that humans are comfortable making predictions very early in their development. These studies showed that by the time babies are six months old they are already making predictions related to their expectations of an object (effect) for which a person should be reaching (cause) (Cannon \& Woodward, 2012). Judea Pearl, a computer engineer and philosopher, argues that historically humans accepted that only "Gods, people and animals could cause things to happen, not objects, events or physical processes" (Pearl, 2009, p. 402). In the ancient world, natural things were predetermined because they were controlled by angry Gods. He argues that it was the engineers, constructing machines to do useful jobs with 
multistage systems, who initiated the notion that one could blame physical objects for any break down in a system. As a result, such objects began to acquire causal character and could then became agents of causation. For causation in science, Pearl argues we have to blame Galileo who argued for an order of practice that is the way practices develop in science today: description followed by explanation and mathematics as the language for describing patterns of observations (laws). He argued that description, the what, should precede the explanation, the why. Rather than asking if an object falls because it is pulled or pushed, Galileo asked whether it is possible to predict the time it takes an object to fall a certain distance, which is how science asks these questions today. Pearl argues further that the use of mathematics, especially algebra, allowed engineers to ask "how to" questions, how can we shape a beam so that it can carry a load, as well as "what if" questions, what happens if we make the beam thinner, will it still carry the load (Pearl, 2009, p. 405). However, such nuanced analysis of cross cutting concepts does not find its way into the Framework.

\section{Disciplinary core ideas}

Not surprisingly Dimension 3, disciplinary core ideas (DCI), was the key focus of the Framework and the subsequent Next Generation Science Standards (NGSS) (Achieve, 2013). In the Framework, these disciplinary core ideas are broken down into Physical Science; Life Science; Earth and Space Science; and Engineering, Technology and Applications of Science. Within the physical science disciplinary core ideas, four sections were identified:

PS1: Matter and its interactions

PS2: Motion and stability: Forces and interactions

PS3: Energy

PS4: Waves and their applications in technologies for information transfer

The student responsible for this set of core ideas represented them in two panels (see Figure 5).

The presentation of disciplinary core ideas in the Framework for all sections of the sciences emphasized that, at each grade band, students would be expected to show increasing levels of competence with these ideas and be better able to describe the interactions that are key to these ideas. The idea of grade band endpoints comes from the exploration of learning progressions associated with these DCIs. Later in this section, I explore the nature of learning progressions and their impact on the NGSS in a more substantive way. 


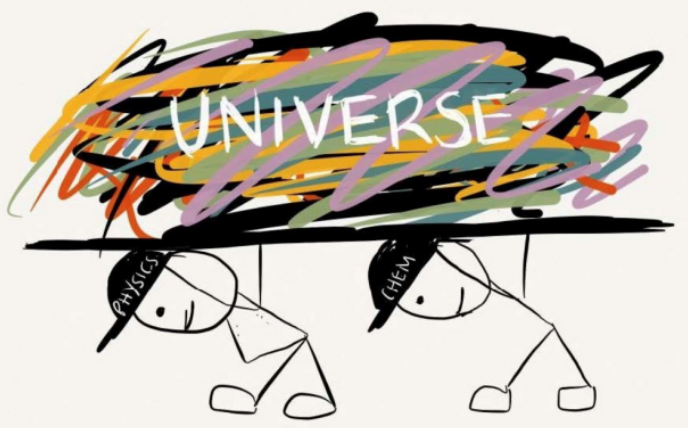

In order to understand $a$ system, we must understand

the interactions at the atomic and subatomic levels
Everything is governed by physical and chemical principles recognize patterns/cause-andeffect when learning Physics!

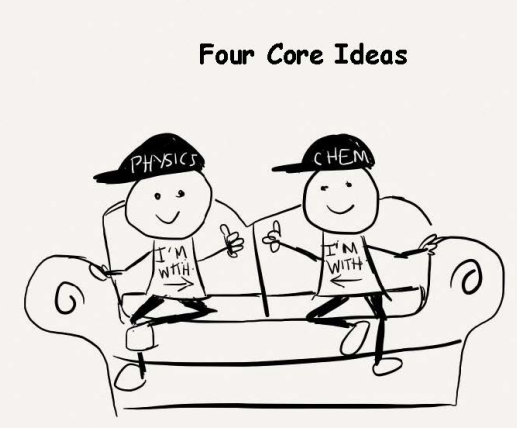

Ideas 1-3: What is

Ideas 1-3: What is
everything made of? Why do things happen?

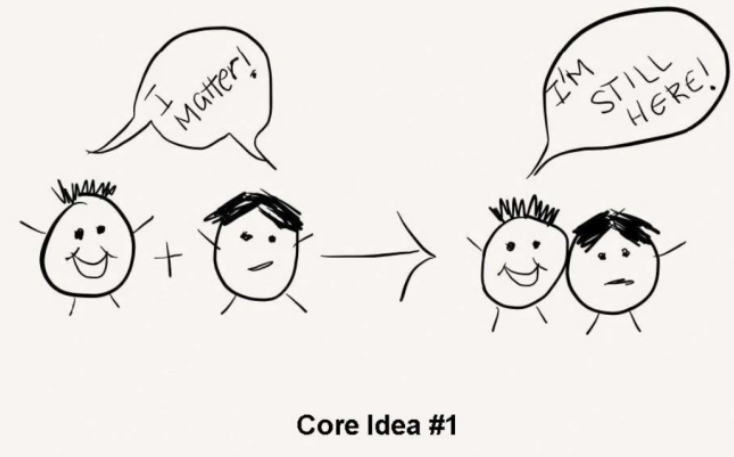

Matter can be understood based on atomic structure and interactions

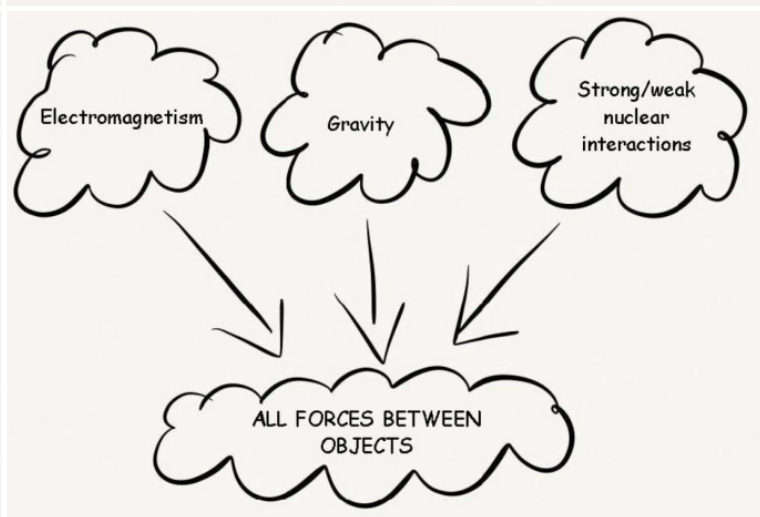

Core Idea \#2

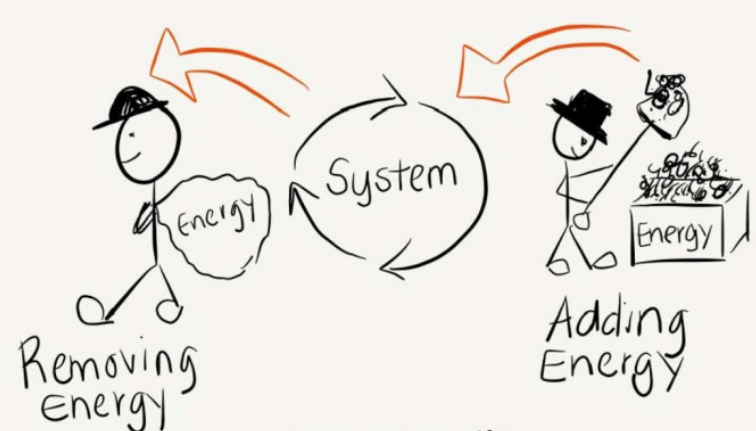
Core Idea \#3
Transfer of energy can explain interactions between objects.
The only way the amount of energy changes is if it is added to
or removed from the system

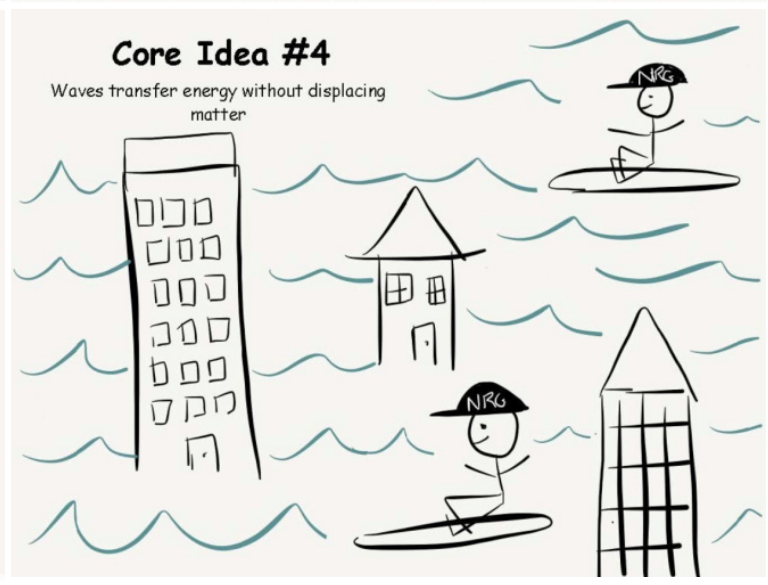

Figure 5. Disciplinary core ideas for Physical Science (NRC, 2012)

\section{Life Science}

For the Life Sciences, the DCIs were:

LS 1. Structures and processes

LS 2. Properties of ecosystems

LS 3. The nature of inheretence and heredity

LS 4. Biological evolution (see Figure 6 for a summary of a section) 


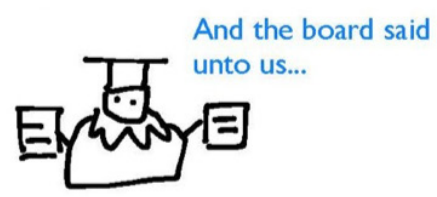
The National Academy
of Science has created a
set of core ideas for
science education

For Life Sciences, it lays out four core ideas, each one broken up into subtopics

The first is Structures and Processes

This idea covers four subtopics

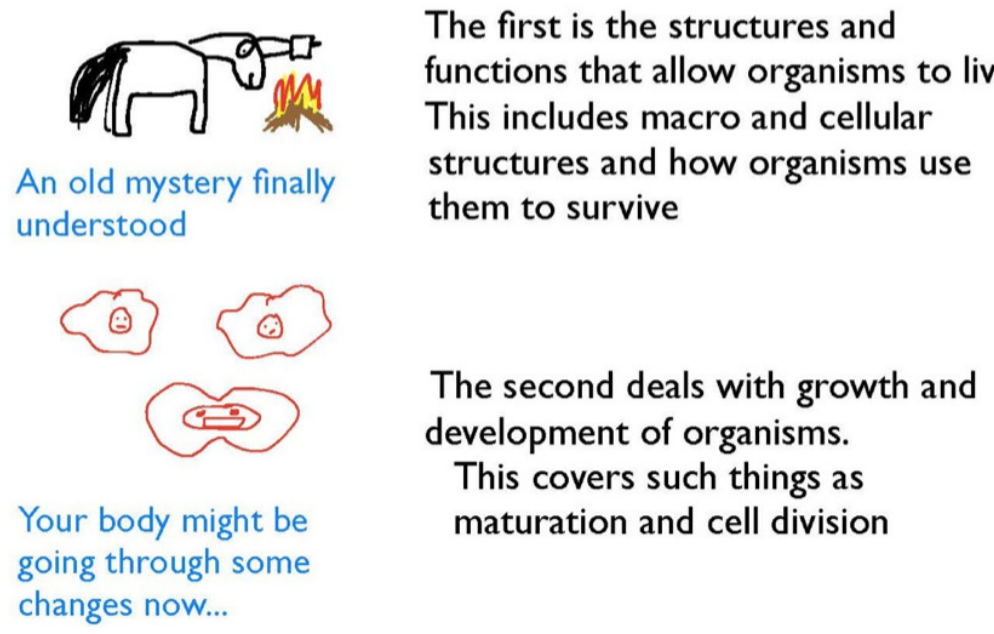

Figure 6. Life science, disciplinary core ideas explained (NRC, 2012)

One of the challenges facing the authors of both the Framework and the NGSS as they articulated a set of life science DCIs was the question of what to include and what to leave out. Their goal was to reduce the number of life science topics, leaving space and time for a curriculum to explore a limited set of DCIs in greater depth hence the need for subtopics.

\section{Earth and Space Science}

Often earth and space science do not get the level of attention in school science that one might expect but in the Framework they constitute one of the central core disciplinary ideas. Earth and Space Science has the goal of supporting students to investigate processes that operate on the Earth and the Earth's place in the solar system, the galaxy, and the universe. Additionally, the Framework notes the interdisciplinary nature of specific sciences that fall within the category of Earth and Space Science.

In order to address the complexity of this category with any level of completeness the authors of the Framework organized the ideas from large spatial scales to small, change over time, and human impact on earth systems (see Figures 7 and 8 ) to get a sense 
of how the graduate students assigned to this chapter of the Framework interpreted it). The major areas of core ideas were:

1. Earth's place in the universe

2. Earth systems

3. Earth and human activity.

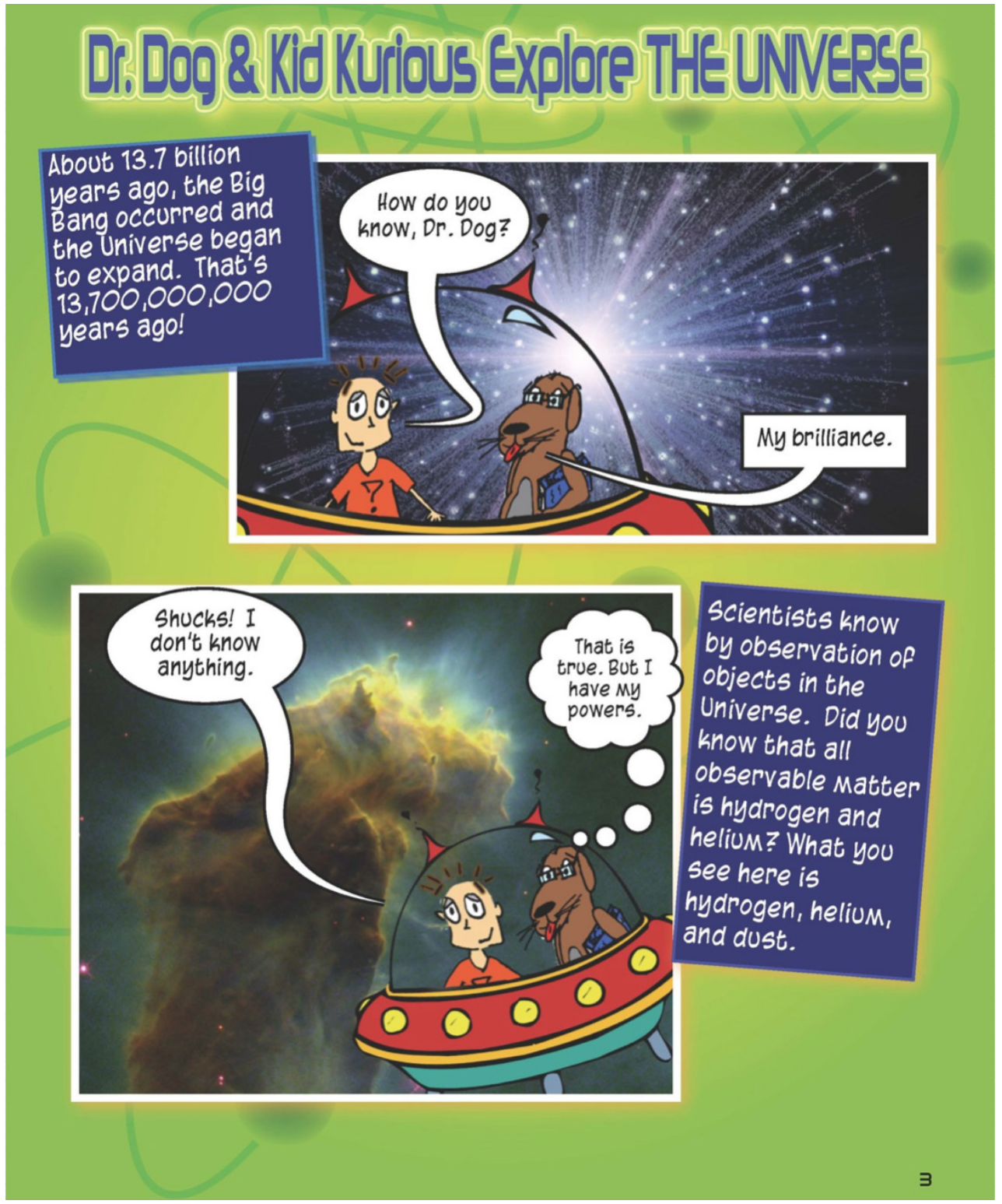

Figure 7. Image show how students interpreted Large spatial scales (NRC, 2012) 


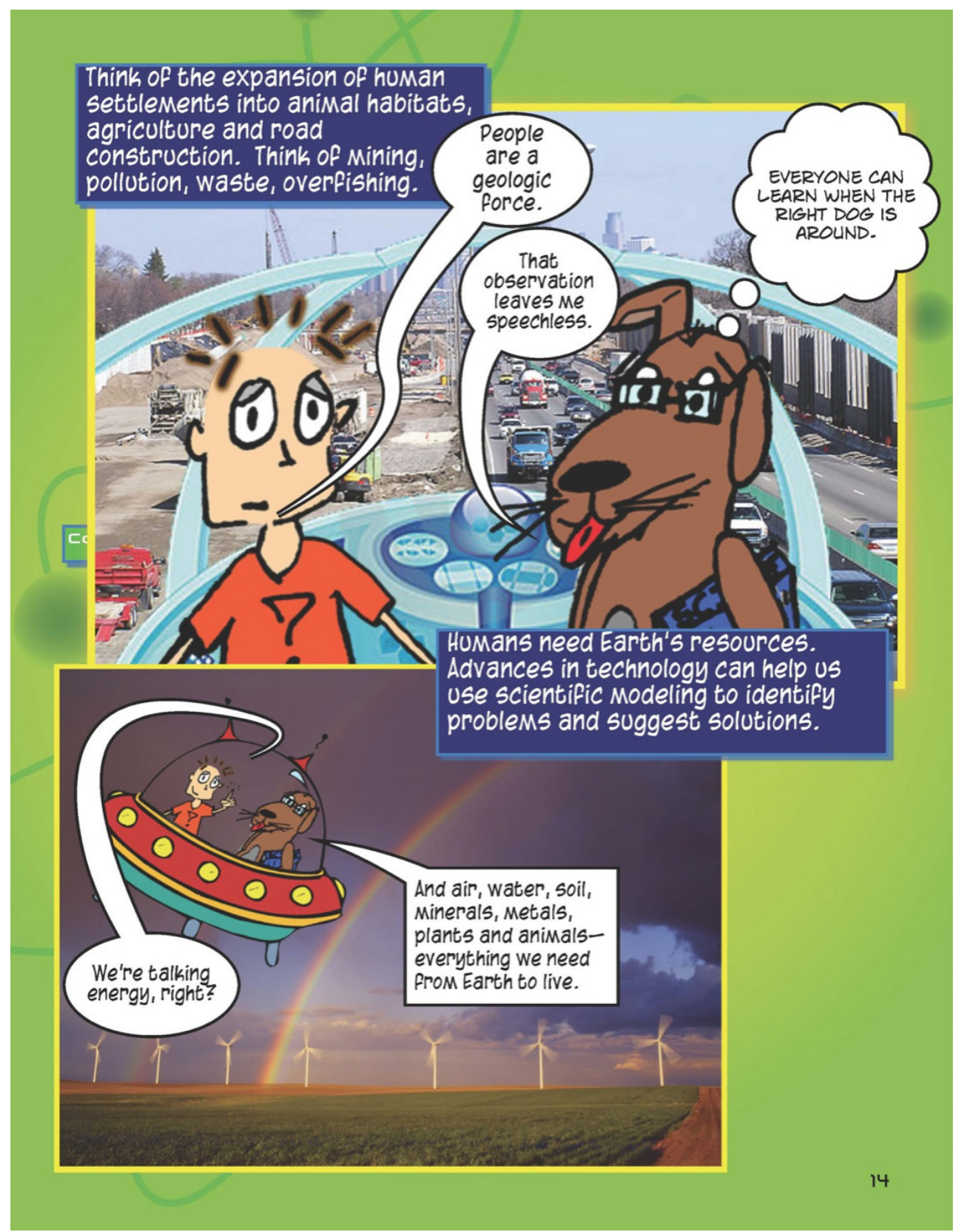

Figure 8. Image show how students interpreted Human impact (NRC, 2012)

Note the modernist take on how science can solve problems including human created ones as students reinterpreted the Framework's presentation of the DCI of Earth and Space Science.

\section{Engineering, technology and applications of science (ETS)}

This section of disciplinary core ideas addresses the question of how science is used in other contexts particularly through the process of engineering design. Technology is defined as a change to the natural world to support human needs or desires and engineering as a process that is systematic and iterative and builds structures or systems 
that allow humans to fulfil their needs and desires (see Figure 9). The two sections are:

1. Engineering design

2. Links among engineering, technology and science on society and the natural world.

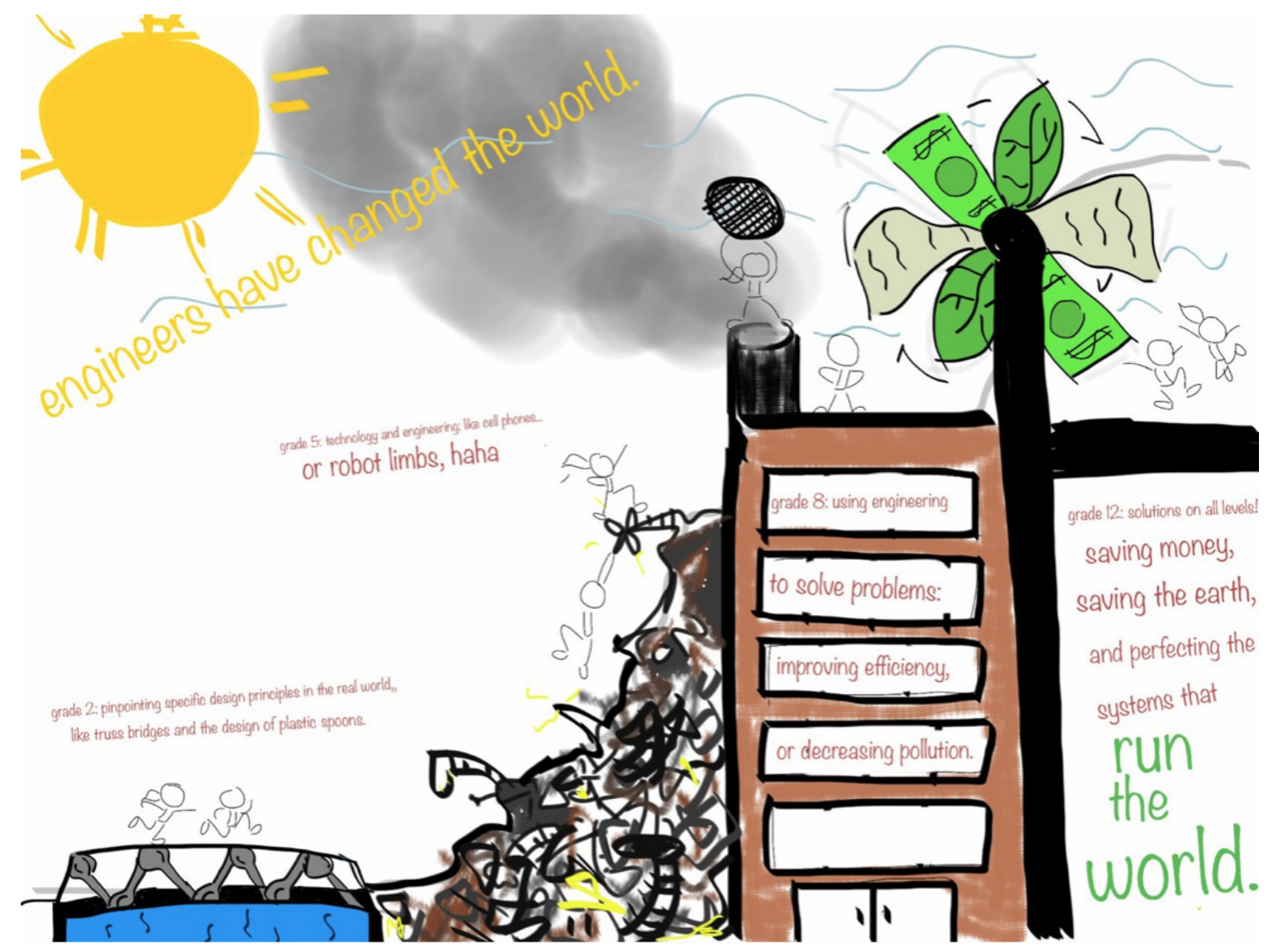

Figure 9. Engineering design and the proposed learning progression that identified milestones for learners at Grades 2 (7 years old), 5 (10 years old), 8 (13 years old) and 12 (17 years old) (NRC, 2012)

Learning Progressions. The graduate students who interpreted this chapter also captured the learning progression and Grade Band endpoints that were included in the chapter on ETS. As the authors of the Framework noted:

For the disciplinary core ideas, we provide a set of grade band endpoints for each component idea that describe the developing understanding that students should have acquired by the ends of grades $2,5,8$, and 12 , respectively. These endpoints indicate how this idea should be developed across the span of the K-12 years. In standards, curriculum, and instruction, a more complete sequence that integrates the core ideas with the practices and crosscutting concepts will be needed (NRC, 2012, p. 33).

These progressions and grade band endpoints were provided for all dimensions 
in the Framework but tended not to be richly developed in that monograph. The authors of the Framework defined a learning progression as a sense of development that takes a student to mastery of a core idea by providing a map of the routes that can be taken to achieve that mastery with the provision of appropriate instructional supports and materials.

Such progressions describe both how students' understanding of the idea matures over time and the instructional supports and experiences that are needed for them to make progress (NRC, 2012, p. 26).

In the NGSS, these progressions and bands were to be fleshed out. However, the NGSS does not contain as many fleshed out learning progressions as you might expect. Learning progressions, also called progress maps by some researchers, imply coherence and continuity through their attempt to present a sequence/continuum of increasing expertise that is based on what the developer thinks is appropriate for learning within a content area. Some of the first progress maps/learning progressions were developed in Australia (see Shepard, Daro, and Stancavage, 2013). As Masters and Foster (1996) note, a progress map describes the knowledge, understandings and skills of a learning area in sequence and in terms of student performances at particular levels of achievement. Thus, in a learning progression, learning and assessment should be integrated. For US audiences, learning progressions made a significant appearance in the NRC publication, Taking Science to School (NRC, 2008).

The idea of a learning progression, although perhaps not known by that name, is most likely not new to experienced teachers who would probably say that they give a lot of thought to the progression of learning of the students they teach. However, for Lorrie Shepard, Phil Daro and Fran Stancavage (2013) the explicit development of learning progressions was, from an assessment perspective, "one of the most important assessment ideas to be introduced in the past decade" (p. 143). Shepard and her colleagues argue further that learning progressions challenge the fixed pace notion of development. She and her colleagues note that in US psychology it was generally accepted that development in children was fixed. However, contemporary research on learning has indicated that learning and development interact so that instructional moves can impact development. Progress maps seek to capture and map this interaction. In an earlier paper, Margaret Heritage (2008) argued, "Curricula are often organized around scope and sequence charts that specify procedural objectives to be mastered at each grade. Usually, these are discrete objectives and not connected to each other in a larger network of organizing concepts (NRC, 2000)" (p.2). She noted that the contents of science and math textbooks in the US are often also designed in this piecemeal superficial way (because of the mass of ideas that are included) that then present content in a way that is fundamentally incoherent. Because learning progressions can be developed over multiple years they offer the possibility of developing a big picture of learning within a particular context that is much more coherent than a scope and sequence chart can ever possibly hope to be. 
Typically, the learning progressions used in the NGSS are what Heritage (2008) calls "top down" progressions because they were developed through input from experts from the discipline and experts from other associated domains such as developmental psychology and cognitive science and from research knowledge of how children learn within elements of this discipline. The resulting progression is based on their ideas, which for me resonates with the approach used in the US to develop curriculum projects in the late 1950s and early 1960s, such as Physical Science Curriculum Study (PSCS), ChemStudy, and Biological Sciences Curriculum Study (BSCS), that were established as a consequence of the US response to the Russian launch of Sputnik. These curriculum developments also involved experts from a range of disciplines but few (none) practicing teachers. The other way of developing learning progressions is having curriculum content experts and teachers collaborate on developing a progression that is based on teachers' intimate experience of how children learn specific content areas, a bottom-up approach to learning progression development. Such a bottom up perspective has a curriculum focus based on teachers' understanding of what should be taught when. Early progress maps developed by the Australian Council of Educational Research (Masters \& Forster, 1996) used this approach. Siobhan Leahy and Dylan Wiliam (2011), in an exploration of how to build learning progressions, argue for a similar "bottom up" approach claiming that, "the development of learning progressions needs to be carried out locally, since learning progressions need to be integrated into teachers' daily practices to be of greatest benefit" (p. 9). For me, this is how learning progressions should be developed, with input from all stakeholders including teachers. However, as I noted previously, that is not the approach used in the Framework for K-12 Science Education (NRC, 2012). Leahy and Wiliam also note the role of national cultural perspectives for influencing learning progressions using an example from a learning progression for finding the areas of triangles and quadrilaterals. In the US, the sequence recommended by the Common Core State Standards (another set of standards to which the NGSS are linked) is that students learn how to calculate the area of rectangles in third grade followed by triangles and parallelograms in sixth grade. The sequence for sixth grade then typically follows: right triangles, other triangles, parallelograms and trapezoids and is a sequence found in many US textbooks. However, for this sequence to "work" teachers need to take care about how they choose their triangles and the methodologies they present to students since obtuse-angled triangles may not fit the with the approach they endorse. In Japan, the pedagogical approach is to teach the area of a parallelogram before area of a triangle because then students can put congruent triangles together to construct a parallelogram, an approach that offers the possibility of supporting students note patterns in their practice and to also generalize between parallelograms and triangles.

A further issue with learning progressions, and one that I have experienced developing a robotics sequence within a physical science learning progression presented in the NGSS, is that the granularity presented in standards documents is not fine enough for use in the planning of classroom lessons. Indeed, in the final version of the NGSS 
(Achieve, 2013), learning progressions are relegated to Appendix E of the document. Even there, no learning progression is provided for the Disciplinary Core Idea (DCI): Motion and Stability: Forces and Interactions, the DCI on which we sought to focus the integration of robotics in Middle School math and science.

I have one final reflection on learning progressions. Although I can appreciate the allure of learning progressions, the versions presented in both Taking Science to School (NRC, 2009) and The Framework for K-12 Science Education (NRC, 2012) with their emphasis on conceptual knowledge seem overly cognitivist and at odds with the avowed emphasis on science and engineering practice as one of the dimensions of the authors' vision for science education. As I have argued previously (Milne, 2011) a focus on conceptual knowledge encourages in school classrooms the presentation of science as finished. One of the consequences of such a presentation is that students can be denied opportunities to experience and to grapple, through practice and experiences, with some of the challenges humans face trying to understand why objects and living things behave the way they do. Often, in science education, concepts are presented as having greater ontological power than the lifeworld experiences of the students themselves. Part of this ontological power is also captured in practices associated with laboratory activities designed to confirm conceptual understandings or scientific facts. Jerome Bruner (1992) discussed this very issue locating science making in problem solving:

What I am proposing, rather, is that our instruction in science from the start to the finish be mindful of the lively processes of science making, rather than being an account only of "finished science" as represented in the textbook, in the handbook, and in the standard and often deadly "demonstration experiment". (p. 10)

Personally, I do wonder if the construct of learning progressions is antithetical to the dimension of scientific and engineering practices. I also wonder why there does not seem to be more effort given to exploring learning progressions from a historical perspective. Using an historical perspective, it might be possible to collect historical evidence of the progression within a specific conceptual area and use that information to integrate practices such as questioning, making claims, developing experiments, generating data and analyzing data with the development of explanatory frameworks. This approach is what I attempted to follow for the relationship between pressure and temperature (see Milne, 2013). Another approach to exploring progressions could use evidence from ethnographies of children at play as a starting point for developing learning progressions. For example, Marjorie Goodwin's (2006) research with girls playing hopscotch and jump rope provides an insight into the role of argument in play. I also wondered why, in trying to develop a learning progression for argumentation, we do not start with this type of ethnographic research instead of seeking to apply Stephen Toulmin's (2003) model for argument as the structure for argument with school learners? For me, a limitation of the way learning progressions are presented in Taking Science to School (2008) and in the Framework (NRC, 2012) is that they were only presented from a cognitivist perspective without consideration of any other approaches to developing 
learning/knowledge progressions. This seems to me to be a serious limitation for attempts to build a holistic vision for learning in science.

\section{Let's integrate}

Learning progressions aside, the authors of the Framework recognized the challenge of integrating the three elements, scientific and engineering practice, crosscutting concepts and disciplinary core ideas in developing curriculum and acknowledged they needed to provide information on how that might be done. According the authors of the Framework (NRC, 2012):

standards guide and shape curriculum, instruction, and assessment, [so] the task of integrating the three dimensions of the framework for K-12 science education begins with the development of standards. A major task for developers will be to create standards that integrate the three dimensions (p. 218).

This statement illustrates the Framework authors' perspective that the need for integration justifies the development of standards statements. In the NGSS, these standards statements contain performance expectations associated with each standard. However, although the recommendation for integration was designed to inform the development of the NGSS and integration remains a focus in the NGSS, within the published standards each dimension remains separate. Graduate students with whom I worked had much more fun communicating some of the challenges facing teachers seeking to integrate all dimensions of the Framework into their practice (see Fig 8). The table in their diagram highlights the challenge of integrating assessment, instruction, curriculum and standards with DCIs, practices and cross-cutting concepts.

If anything, I feel that the students' presentation of the challenges and a possible solution might actually have supported greater levels of integration than can be currently observed in the NGSS. For me, there is a powerful tension between the idea of learning progressions, of whatever form they take, and the integration of the three dimensions when stepped standards constitute the presentations of the standards in the NGSS. This tension is also acknowledged in the Framework:

Standards and performance expectations that are aligned to the framework must take into account that students cannot fully understand scientific and engineering ideas without engaging in the practices of inquiry and the discourses by which such ideas are developed and refined [1-3]. At the same time, they cannot learn or show competence in practices except in the context of specific content (p. 218).

In the chapter of the Framework on guidance for standards developers the authors outlined the purpose of standards, which we captured in our graphic version of the chapter (see Figure 10).

While the standards are designed to communicate educational priorities, in the NGSS they are presented in the form of performance expectations which could form the basis of assessment. One of the kindergarten school performance expectation (KPS-2 - 
Kindergarten Physical Science 2) from the NGSS for the standard Motion and Stability: Forces and Interactions (see Figure 10) shows how the integration of the dimensions was built into a performance expectation.

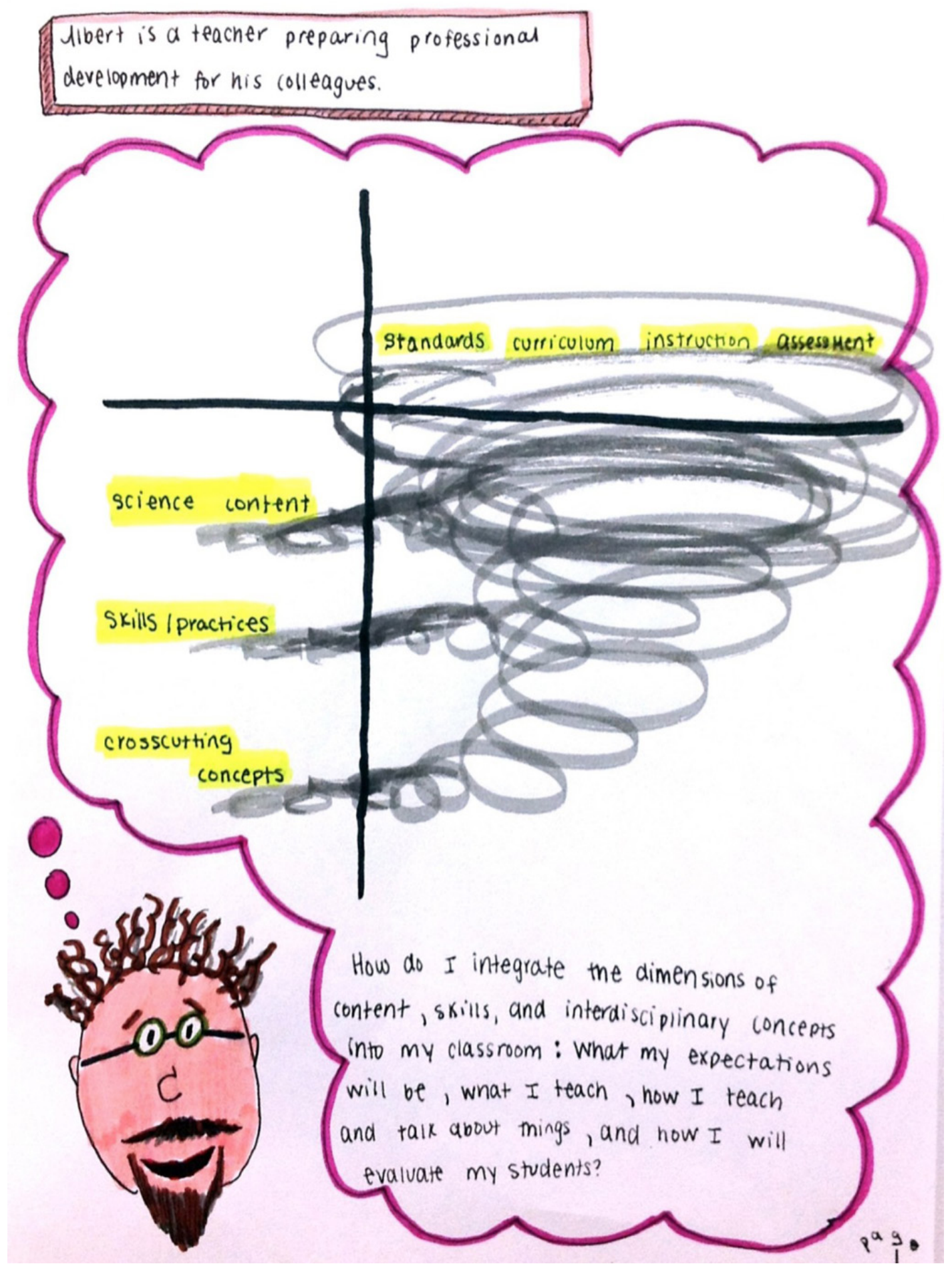

Figure 10. The big integration question (NRC, 2012) 


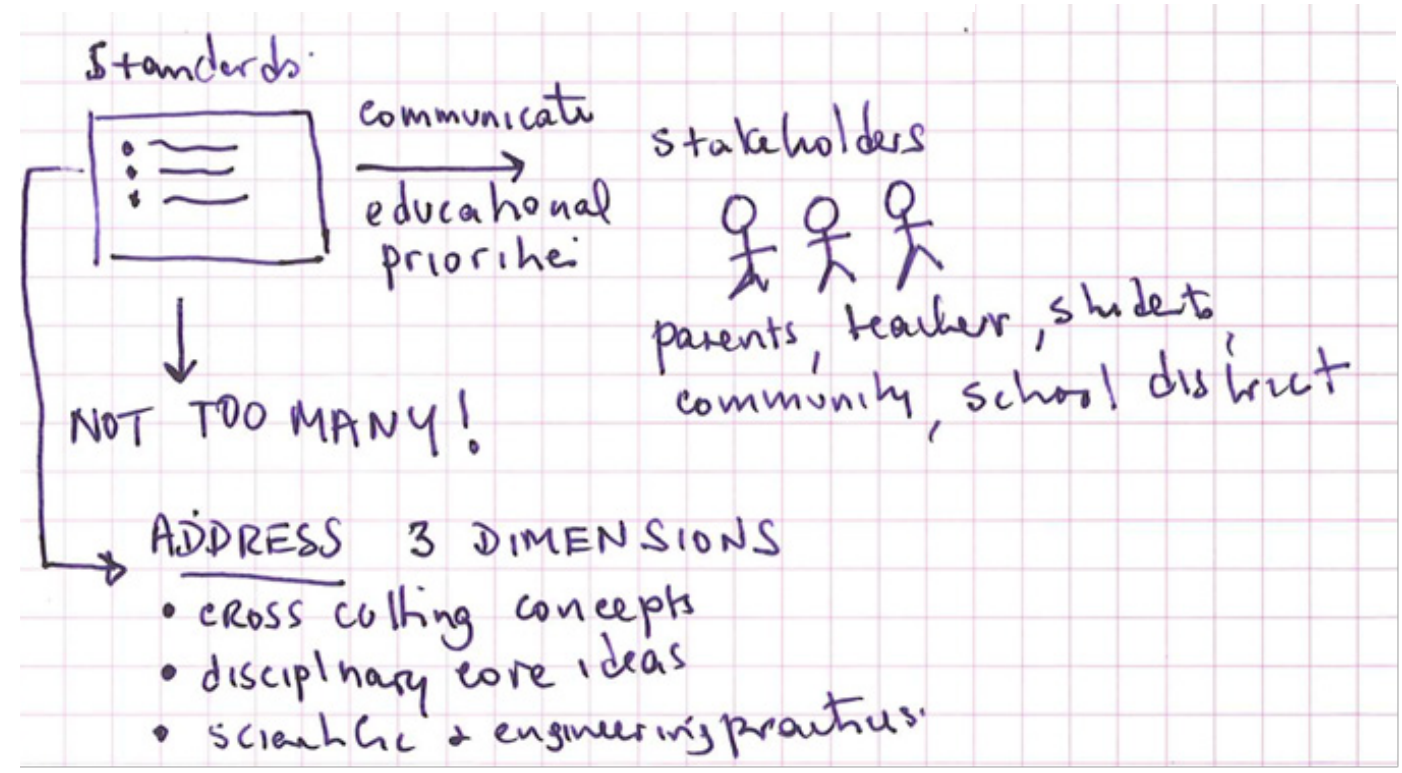

Figure 11. Some recommendations by Framework authors for standards developers! (NRC, 2012)

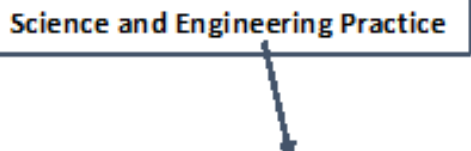

Crosscutting Concept

Cause and effect

Analyze data to determine if a des ign solution works as intended to change the speed or direction of an object with a push or a pull.* [Clarification Statement:

Examples of problems requiring a solution could include having a marble or other object move a certain distance, follow a particular path, and knock down other objects. Examples of solutions could include tools such as a ramp to increase the speed of the object and a structure that would cause an object such as a marble or ball to turn.] [Assessment Boundary: Assessment does not include friction as a mechanism for change in speed.]

Disciplinary core idea - a push or a pull (a force) is needed to change the speed or direction of an object

Bound ary statement

Elementary performance expectation for Standard: Motion and Stability: Forces and Interactions

Figure 12. Standard converted to Performance Expectation, KPS-2, for Kindergarten Elementary Science (Achieve, 2013)

In this performance expectation, note the challenge of integrating all the dimensions into one statement and the identification of what the Framework authors called boundary statements that identify, for those using the expectations as a guide for practices, core ideas and cross-cutting concepts what should be included and what should be left out. For example, in this case children are not expected to use the term, "friction" as an explanatory mechanism. However, there is also no mention made of 
"force" as an explanatory idea. Yet I would anticipate that elementary grades students would have experienced and most likely used this term in their everyday lives. Based on the Framework's focus on learning progressions you might expect that this performance expectation would build on to the next performance expectation for this standard, which in the NGSS is presented at Grade 3, and again when it is presented at Grade 5, Middle School, and High School (see Figure 11). However, I challenge any reader to identify such a progression through these performance expectations.

\begin{tabular}{|l|l|l|}
\hline Grade & Performance Expectation & $\begin{array}{l}\text { Core Disciplinary } \\
\text { Idea (?) }\end{array}$ \\
\hline 3 & $\begin{array}{l}\text { Make observations and/or measurements of an object's motion } \\
\text { to provide evidence that a pattern can be used to predict future } \\
\text { motion. [Clarification Statement: Examples of motion with a } \\
\text { predictable pattern could include a child swinging in a swing, a ball } \\
\text { rolling back and forth in a bowl, and two children on a see-saw.] } \\
\text { [Assessment Boundary: Assessment does not include technical terms } \\
\text { such as period and frequency.] }\end{array}$ & Harmonic motion \\
\hline 5 & $\begin{array}{l}\text { Support an argument that the gravitational force exerted by } \\
\text { Earth on objects is directed down. [Clarification Statement: } \\
\text { "Down" is a local description of the direction that points toward } \\
\text { the center of the spherical Earth.] [Assessment Boundary: } \\
\text { Assessment does not include mathematical representation of } \\
\text { gravitational force.] }\end{array}$ & $\begin{array}{l}\text { Gravitational } \\
\text { force }\end{array}$ \\
\hline $\begin{array}{l}\text { Middle } \\
\text { School }\end{array}$ & $\begin{array}{l}\text { Plan an investigation to provide evidence that the change in } \\
\text { an object's motion depends on the sum of the forces on the } \\
\text { object and the mass of the object. [Clarification Statement: } \\
\text { Emphasis is on balanced (Newtons First Law) and unbalanced } \\
\text { forces in a system, qualitative comparisons of forces, mass and } \\
\text { changes in motion (Newtons Second Law), frame of reference, and } \\
\text { specification of units.] [Assessment Boundary: Assessment is limited } \\
\text { to forces and changes in motion in one-dimension in an inertial } \\
\text { reference frame and to change in one variable at a time. Assessment } \\
\text { does not include the use of trigonometry.] }\end{array}$ & $\begin{array}{l}\text { Newton's first and } \\
\text { second Laws } \\
\text { Inertia }\end{array}$ \\
\hline $\begin{array}{l}\text { High } \\
\text { Grades } \\
\text { 9-12 }\end{array}$ & $\begin{array}{l}\text { Use mathematical representations to support the claim that the } \\
\text { is no net force on the system. [Clarification Statement: Emphasis } \\
\text { is on the quantitative conservation of momentum in interactions } \\
\text { and the qualitative meaning of this principle.] [Assessment } \\
\text { Boundary: Assessment is limited to systems of two macroscopic } \\
\text { bodies moving in one dimension.] }\end{array}$ & $\begin{array}{l}\text { Momentum } \\
\text { (conservation) in } \\
\text { straight lines }\end{array}$ \\
\hline
\end{tabular}

Figure 13. Performance expectations for the Standard - Motion and Stability: Forces and Interactions by grade level (Achieve, 2013)

Although these examples show that in the NGSS there is a numbered sequence of performance expectations from elementary to middle school to high school for the standard Motion \& Stability: Forces \& Interactions, I think you will agree with me that 
they do not represent a learning progression for that standard. Note that as we progress through the grades students are taken from forces, to harmonic motion, to gravitational force, to Newton's first and second laws, to momentum. I ask you, how does such a progression represent coherence in scientific thinking? Certainly, as an experienced high science teacher, I probably would not have selected this sequence as the basis for developing curriculum and assessment.

This standard, Motion \& Stability: Forces \& Interactions, was the one the engineer and I thought offered the best potential for integrating science disciplinary core ideas that were key for building engineering and science practices in robotics. For example, science core ideas, such as simple machines and center of mass, which my engineering expert considered key for building engineering understanding, are not part of the NGSS. I accept that it is always easy to critique a set of standards because they will never be all things to all people however, the performance expectations that were developed for this standard emphasize a specific focus on specific disciplinary core ideas that seem idiosyncratic, not ones that have been developed from deep and extensive input from across the discipline of science education. Indeed, when the NGSS were released for review only four weeks were allowed for feedback, certainly not enough time to experimentally, empirically, and experientially test the sequences that were developed as performance expectations.

To look at another example, consider the Energy standard and energy transfer. In this case, the performance expectation focuses solely on one form of energy transfer, thermal/kinetic energy transfer through temperature measurements and yet there are many other examples of energy transfer that are just as important to students' everyday lives. One that immediately comes to mind is energy transfer in the form of electricity from a battery to a light bulb or an LED. Other important processes for transferring energy include radiation, sound and mechanical work. Together, these examples highlight what is missing from the NGSS and suggest that there is a lot of work to do before these standards can be appropriately integrated by all science teachers of all experience levels into their pedagogy.

\section{Let's implement the Framework and associated standards}

The authors of both the Framework (NRC, 2012) and the NGSS (Achieve, 2013) argue that the standards represent a vision for K-12 science education. For this vision to influence science education, it needs to permeate the education system, and inform curriculum, pedagogy, teacher education and assessment. However, for this vision to become prat of educational practice in schools across the US, the Framework authors acknowledged the importance of the federal government in influencing education through legislation, incentives and other forms of support. The authors of our alternative version of the Framework captured this well (see Figure 14). 


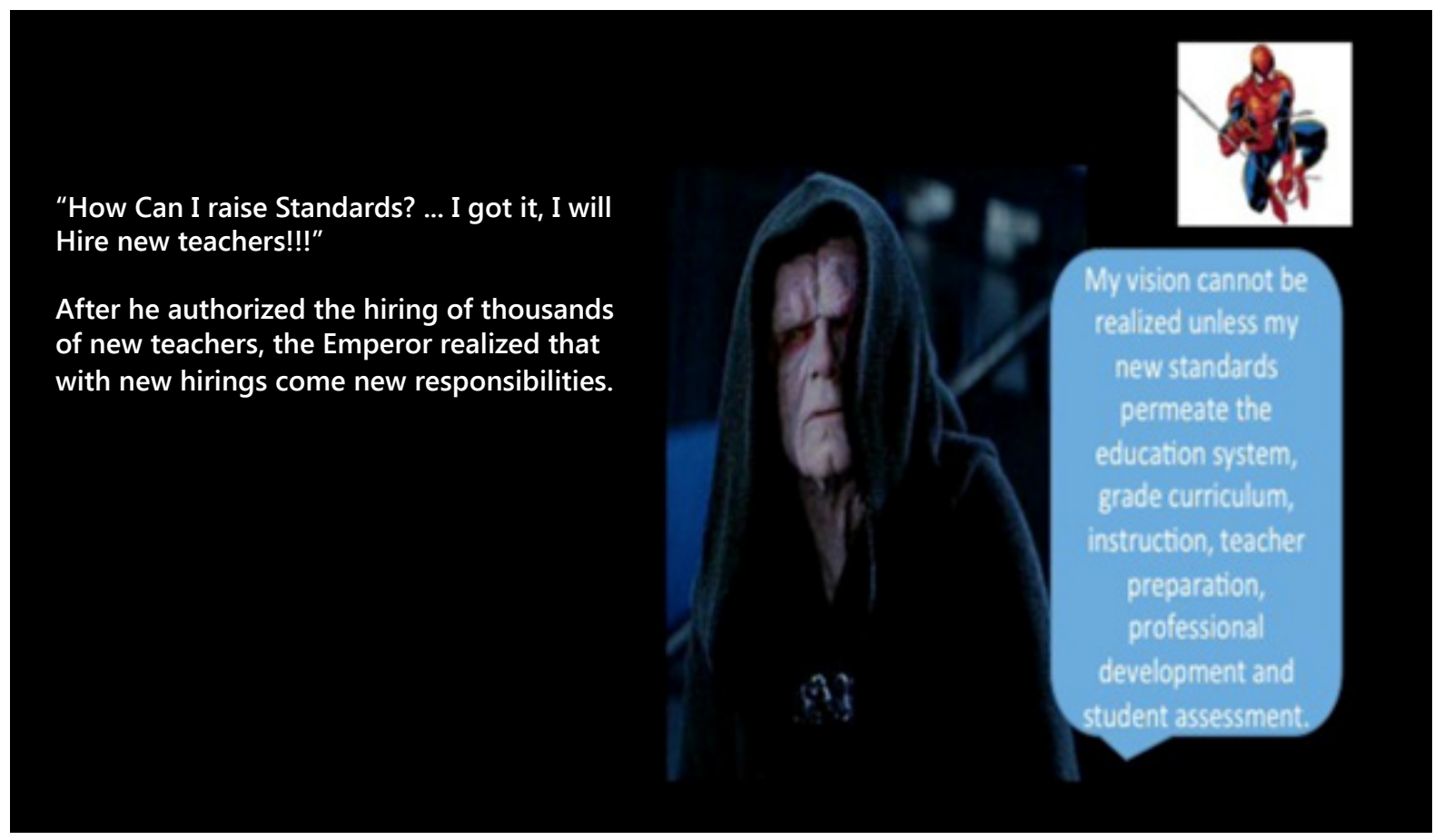

Figure 14. One of the steps to implementation (NRC, 2012)

Framework authors also identified the importance of system-wide coherence that requires all components across levels to work together to achieve a shared vision for education. While some curriculum developers define coherence in terms of alignment, the authors of the Framework were explicit in their stance that coherence was the broad concept with alignment just one of the elements. They argued for horizontal coherence so that curriculum, instruction and assessment are aligned with the standards and vertical coherence so that across different levels of the system there was a shared acceptance of the goals of science education. But even with such a narrow definition for curriculum, the Framework presents a very instrumental perspective of curriculum as "the knowledge and practices in subject matter areas that teachers teach and that students are supposed to learn" (NRC, 2012, p. 246). In our work with prospective science teachers, we find that requiring students to use content storylines to develop units of study and lessons assists them to develop more coherent curriculum and instruction (Milne, Wallace \& Doucet, 2017). Because even if we use standards in the curriculum we need to be able to tell the story of the performance expectations within the standards in a way that supports learners to make connections between the expectations.

When the Framework with its three dimensions of science and engineering practices, cross-cutting concepts and disciplinary core ideas was first proposed, I was very excited and hopeful that science education might, through a focus on practice be seen as something that all learners could do as learners were placed in a science making situation. However, the Framework makes it very clear that the metaphor for the development of the next generation of science standards is not a three-legged stool with the dimensions as the legs equally contributing to a new school science curriculum that is 
the seat. Rather the DCIs are seen as the central core with the practices and cross-cutting concepts radiating out, still important [one cannot have a wheel without spokes] but in that metaphor not contributing equally to a strong structure, leading me to see the NGSS as an opportunity missed for revising how we think about science education in the US.

\section{Equity and Diversity}

Interestingly, but perhaps not surprisingly considering all I have said so far, a discussion of equity and diversity does not come in the Framework until almost the end of the document. I do wonder why greater effort was not given to integrating an exploration of issues of equity with the presentation of the three dimensions of science education in both the Framework and the NGSS. One issue that bedevils education in the US is the way school funding is organized through property taxes which are administered at the local government level. Even with changes to a minimum level of funding for schools, schools in wealthy neighborhoods are still advantaged (Samuels, 2016). But with a separate chapter on equity, we are no closer to understanding how such integration might occur in the Standards themselves. Indeed, in the NGSS, the equity element is presented in Appendix D: "All standards, all students". This presentation of equity and diversity as a separate section communicates a lack of attention given to working on integrating these constructs into the actual content of the NGSS.

On one issue I do agree with the Framework. I do believe that all students can learn science "especially if it [science] connects to areas of personal interest and consequence" (NRC, 2012, p. 280), which is one reason why I would like to see a greater focus on scientific and engineering practices in the science curriculum. In the past, and perhaps even now, equity was focused on access to resources and when that access did not seem to make a difference it was easy to blame the learner. This deficit model of blaming the victim still has some traction in education contexts. Additionally, writers of learning standards in a discipline often struggle with the challenge of how to represent the discipline in a way that is faithful to the nature of the discipline while also providing space for learners to identify with the discipline. Even if one believes, as Science generally does, that there is something real with which we interact and that part of the reason Science exists as a discipline is because it has a responsibility to try to explain this reality that humans observe, Science also understands that the process of building explanations is a dialogic reflexive one between participants, nature, society and culture writ both large and small (Milne, 2011). In other words, Science exists because it is part of the human condition and not separate from it. As Barton (1998) noted for the previous version of the NGSS, the National Science Education Standards, but which still seems relevant for the NGSS, one science does not fit all. Therefore, there is no such thing as an essential normative science education into which we shoehorn all children. Instead we should be building a science education in which children and youth can find a place and a space for themselves and a science education that is changed by their input into its structure, so that it is becomes truly dialogic. 


\section{Challenges for the NGSS and for any national standards}

In this paper, I have worked to present an idiosyncratic perspective on the development of the Next Generation Science Standards, which represents the current attempt to develop a set of national standards for K-12 school science in the United States. My initial reaction to the Framework for K-12 Education (2012) was positive because I was excited by the notion of the three dimensions that were being presented as elements of school science. However, a deeper reading of the Framework and the NGSS led me to highlight some of concerns I have with the focus of the NGSS. I do think that the NGSS represents a missed opportunity to perhaps go in a different direction, focusing more on science and engineering practices than disciplinary core ideas. In the Front Matter the authors of the NGSS say, "The NGSS content is focused on preparing students for college and careers" (Achieve, 2013, p. 2). However, most students are not preparing for careers in science, so perhaps whatever science curriculum one develops should prepare students to see science as providing tools for being engaged as a citizen scientist. From my perspective, what is missing from the NGSS is the human role in the construction of science. For example, women experimental philosophers are ignored and men, although they leave their name in the standards, have their struggles and their questions ignored in the presentation of ahistorical standards in the NGSS. In the NGSS, Science is not presented as a human endeavor but as a set of conceptual ideas handed down from somewhere that is never presented through practice, described through observation or explained through theorizing, all practices that are key scientific practices.

Another tension associated with any set of national or de facto national standards like the NGSS exists around a desire to support a culturally relevant curriculum that captures local interests and questions through place-based education when science is usually presented as a global discipline where what counts as knowledge and practice is the same everywhere on Earth and in the Universe. While one might argue that physical phenomena behave in a similar way throughout the universe and the search for universal laws is an ongoing goal of physics (see Feynman, 1967), the importance we attach to such laws is inevitably local. The challenge becomes a question of how do educators incorporate the local and the global into standards for science education? What purpose is served with the development of national standards? And if a nation decides that standards are necessary for issues of equity, where do educators make the cuts to decide what to include and what to leave out in developing standards for science education?

I think in considering how to build a set of standards that can become the basis for a national science curriculum we (educators) are left with questions including the following: what should a national curriculum be like? what are the key scientific ideas and practices that allow citizens to contribute in thoughtful ways as national and global citizens who can also, should they wish, continue studies to be scientists, engineers, and technologists? why have educators become locked in to a cognitivist perspective of how one comes to know and is that the only way educators can envisage learning and/ 
or epistemology or are there other at least equally productive and perhaps more useful ways of thinking for your educational context? For me, these are some of the questions that should have been asked as we in the US began thinking about the Next Generation Science Standards but did not, at least not obviously. For me, these are questions that exist at the center of any decisions in Brazil for the development of a set of national standards for science education. Inevitably, crisis narratives that decry the current educational situation are used to goad a rapid response to the apparent need for change in an educational system. However, I hope that this paper encourages you to critically examine proposed new standards or national curricula to ensure that it remains loyal to the principles of education that constitute part of your identity as an educator.

\section{References}

Achieve Inc. (2013). Next Generation Science Standards. Achieve Inc.

Barton, A. C. (1998). Reframing "Science for All" through the politics of poverty. Educational Policy, 12, 525-541. DOI: 10.1177/0895904898012005004

Bruner, J. (1992). Science education and teachers: A Karplus lecture. Journal of Science Education and Technology, 1, 5-12.

Cannon, E. N. \& Woodward, A. L. (2012). Infants generate goal-based action predictions. Developmental Science, 15, 292-298. 10.1111/j.1467-7687.2011.01127.x

Edwards, R. (2008). Education - an impossible practice? Scottish Education Review, 40, 4-11.

Feynman, R. (1967). The character of a physical law. Cambridge, MA: MIT Press.

Heritage, M. (2008). Learning progressions: Supporting instruction and formative assessment. Paper prepared for the Formative Assessment for Teachers and Students (FAST) State Collaborative on Assessment and Student Standards (SCASS) of the Council of Chief State School Officers (CCSSO) Washington, DC.

Leahy, S., \& Wiliam, D. (2011). Devising learning progressions. Paper presented in the Symposium on How to Build Learning Progressions at the annual meeting of the American Educational Research Association, New Orleans, LA, April 2011.

Goodman, M. (2006). The hidden life of girls: Games of stance, status, and exclusion. Oxford: Blackwell.

Masters, G. \& Forster, M. (1996). Progress maps. (Part of the Assessment Resource Kit) Melbourne, Australia: The Australian Council for Educational Research, Ltd.

Milne, C. (2011). The invention of science: why history of science matters for the classroom. Dordrecht, The Netherlands: Sense Publishers. 
Milne, C. (2013). Creating stories from history of science to problematize a scientific practice: A case study of boiling points, air pressure, and thermometers. Paper presented at the 12th biennial International History, Philosophy and Science Teaching conference, University of Pittsburgh, USA, June 19-23, 2013.

Milne, C. (2017). Why materials matter: Exploring the role of instruments in learning science. In C. Milne \& K. Scantlebury (Eds.) Material practice and materiality: Too long ignored in science education. Dordrecht: Springer

Milne, C., Wallace, R., \& Doucet, F. (2017). On not getting lost: The educational value of using con,tent storylines in curriculum development, pedagogy and assessment. Dialogic presentation at the American Association for Colleges of Teacher Education meeting, Tampa, FL, February, 2017.

National Research Council. (2006). America's Lab Report: Investigations in High School Science. Committee on High School Science Laboratories: Role and Vision, S.R. Singer, M.L. Hilton, and H.A. Schweingruber, (Eds). Board on Science Education, Center for Education. Division of Behavioral and Social Sciences and Education. Washington, DC: The National Academies Press.

National Research Council. (2007). Taking Science to School: Learning and Teaching Science in Grades K-8. Committee on Science Learning, Kindergarten Through Eighth Grade. Richard A. Duschl, Heidi A. Schweingruber, and Andrew W. Shouse, (Eds.). Board on Science Education, Center for Education. Division of Behavioral and Social Sciences and Education. Washington, DC: The National Academies Press.

National Research Council. (2009). Learning Science in informal environments: People, places and pursuits. Committee on Learning Science in Informal Environments. P. Bell, B. Lewenstein, A. W. Shouse, \& M. A. Feder (Eds.). Board on Science Education, Center for Education. Division of Behavioral and Social Sciences and Education. Washington, DC: National Academies Press.

National Research Council. (2012). A Framework for K-12 Science Education: Practices, Crosscutting Concepts, and Core Ideas. Washington, DC: The National Academies Press.

Osborne, J. (2014). Teaching scientific practices: Meeting the challenge of change. Journal of Science Teacher Education, 25, 177-196. doi: 10.1007/s10972-014-9384-1

Pearl, J. (2009). Causality: Models, reasoning, and inference. Cambridge University Press: New York.

Pratt, H. (2013). The NSTA reader's guide to a Framework for K-12 Science Education. 2nd Ed. Washington, DC.: NSTA Press.

Ravitch, D. (2013). Reign of error. The hoax of the privatization movement and the danger to America's public schools. New York: Alfred A. Knopf. 
Samuels, A. (2016). Good school, rich school; bad school poor school: Inequality at the heart of America's education system. The Atlantic, August 25, 2016. Accessed at: https://www.theatlantic.com/business/archive/2016/08/property-taxes-and-unequalschools/497333/

Shepard, L., Daro, P., \& Stancavage, F. (2013). The relevance of learning progressions for NAEP. Commissioned by the NAEP Validity Studies (NVS) Panel. Accessed at: www.air. org/common_core_NAEP.

Slater, G. B., \& Griggs, C. B. (2015). Standardization and subjection: An autonomist critique of neoliberal school reform. Review of Education, Pedagogy, and Cultural Studies, 37, 438-459, doi: 10.1080/10714413.2015.1091259

Stoehr, K. J. (2017). Mathematics anxiety: One size does not fit all. Journal of Teacher Education, 68, 69-84.

Toulmin, S. (2003). The uses of argument. Cambridge: Cambridge University Press.

\section{Catherine Milne}

http://orcid.org/0000-0001-8789-5115

Department of Teaching and Learning

New York University

New York City, US

cem4@nyu.edu 